\title{
Identifying new concepts for innovative lighting-based interventions to influence movement and behaviours in train stations
}

\author{
N Hughes $\mathrm{PhD}^{\mathrm{a}^{*}}$, B Ryan $\mathrm{PhD}^{\mathrm{a}}, \mathbf{M}$ Hallewell $\mathrm{PhD}^{\mathrm{a}}, \mathbf{N}$ Coad $\mathrm{MSc}^{\mathrm{b}}, \mathbf{A}$ Grant ${ }^{\mathrm{c}}, \mathbf{N}$ Parrott \\ $\mathrm{HNC}^{\mathrm{c}}, \mathbf{S}$ Roberts $\mathrm{PhD}^{\mathrm{d}}, \mathbf{K}$ Thompson MEng ${ }^{\mathrm{e}}$ \\ ${ }^{a}$ Human Factors Research Group, Faculty of Engineering, University Park, University of \\ Nottingham, NG7 2RD \\ ${ }^{\mathrm{b}}$ Urban Control Ltd, Urban Control Ltd, Pindar Road, Hoddesdon, Hertfordshire, EN11 0DX \\ ${ }^{c}$ DW Windsor, Pindar Road, Hoddesdon, Hertfordshire, EN11 \\ ${ }^{\mathrm{d}}$ Nottingham Geospatial Institute, Faculty of Engineering, Jubilee Campus, University of \\ Nottingham, NG7 2TU \\ ${ }^{\mathrm{e}}$ Rail Safety and Standards Board (RSSB), The Helicon, One South Place, London EC2M \\ 2RB
}

Short Title: Lighting to influence movement in train stations

Received 25 September 2019; Revised; Accepted

The disorderly and disrupted movement of passengers within train stations are key concerns in rail transport, especially where there are increasing numbers of passengers, coupled with often out-dated, adapted station spaces. With careful planning and design, different characteristics of lighting can be employed to address problems relating to the movement and behaviour of passengers in railway environments. This study aims to offer an approach to identifying new concepts for lighting-based interventions, to influence passenger movement behaviours within train stations. Behaviourally-orientated lighting literature was reviewed, providing the knowledge base to inform a series of engagement activities with transport stakeholders and lighting technologists, to understand problematic behaviours and how these might be resolved through targeted lighting design. In combining findings from the literature with insights from rail and transport related industry stakeholders and lighting specialists, a number of potential opportunities for novel applications of lighting have been identified. Six scenarios are developed that illustrate these opportunities for potential lighting-based interventions to influence train passenger movement and behaviour. These scenarios can be used to inform the direction of further research and consideration of how different lighting characteristics can affect rail passenger behaviours.

Corresponding author: Nancy Hughes, Human Factors Research Group, Faculty of Engineering, University Park, University of Nottingham, NG7 2RD.

Nancy.Hughes@nottingham.ac.uk 


\section{Introduction}

Lighting is an important factor in the design of any space occupied or accessible to people. However, the focus when designing new lighting or assessing existing lighting, is typically performance related; for example, is there adequate lighting to support visual acuity and to enable a task or activity to be carried out effectively (i.e. visual and task performance ${ }^{1}$ )? Health and safety related concerns are also relevant, from the potentially harmful effects of flicker (e.g. generalised malaise to more serious epileptic seizures ${ }^{2}$ ), through to its contributory role in slips, trips and falls, particularly for the elderly who may suffer with reduced vision. ${ }^{3}$ Such performance and health and safety related drivers are themselves supported by a number of lighting standards and guidelines (e.g. ${ }^{4,5}$ ). These offer minimum or recommended lighting levels, primarily illuminance and luminance values, for performing a particular task or activity in a particular environment (often indoor).

Whilst such objective requirements in lighting are critical, the role of more aesthetically-driven, experience-based lighting is also recognised. So and Leung ${ }^{6}$ referred to the design of lighting as 'a piece of work related to science and art' (p.113), whilst Manav and Yener ${ }^{7}$ comment on the aesthetical and emotional reactions that arise when observing a lighting system. Lighting design for the creation of atmosphere, to encourage engagement and engender positive responses is of growing interest. Indeed, there is emerging research into both the psychological/behavioural effects and the physiological effects of light (including photobiology, human-centric lighting ${ }^{8}$ ). de Kort and Veitch ${ }^{9}$ argue all classes of effects based on both non-image forming light (influencing circadian and acute effects) and image forming (influencing visual performance, visual experience and visual comfort), ultimately affect psychological functioning, including behaviours and experiences. However, with the exception of some specific environments/contexts e.g. retail, ${ }^{10}$ hospitals, ${ }^{11}$ office spaces, ${ }^{12}$ and the use of dynamically operated arrow-like stimuli in steering festival crowds, ${ }^{13}$ there are few applications of lighting to influence behaviour and/or mood within real-world contexts. Multiple lighting characteristics (intensity, colour, flicker/flash rate) have typically been manipulated and examined in indoor laboratories or Virtual Reality scenarios and often with singular participants. Thus ecological validity and generalisation of this research area to real-world contexts is challenged.

Aside from the recent studies on the use of blue lighting in suicide prevention ${ }^{14-16}$ and emergency egress in road ${ }^{17}$ and rail tunnels ${ }^{18}$, there still remains relatively little guidance relating to the applications of lighting in influencing behaviour in transport contexts, and more specifically rail locations, despite a number of behaviour related challenges that lighting 
could potentially address. For example, there is evidence that changes in lighting can have impacts on walking speed, ${ }^{19}$ mood and levels of activation, ${ }^{20}$ and route selection. ${ }^{21,22}$

The movement and flow of passengers within train stations offers many challenges within the rail industry in Great Britain. Rail stations exist in a variety of sizes, with many comprising a mix of more modern and older or 'heritage' buildings, indoor and outdoor spaces (including canopies) and operating day and night, with significant fluctuations (e.g. at peak/off-peak travel times) and overall increases in passenger numbers. Such dynamic demands, combined with an often out-dated infrastructure, have served to create problems for passenger movement and flow, with crowding on platforms, bunching at intersections and blockages on stairways and bridges at different times of day.

Improvements in this area have the potential to deliver benefits of $£ 258 \mathrm{~m}$, by increasing capacity, enhancing customer experience and efficiency savings. ${ }^{23}$ Whilst these problems have often been addressed using physical interventions (e.g. barriers, use of loudhailers and messages via technological Customer Information Systems), these solutions are expensive, difficult to install and are often implemented without further evaluation to assess their relative impact or effectiveness. ${ }^{24,25}$ This article considers the prospect of using different characteristics of lighting to influence the movement and behaviours of passengers in a rail context, as a dynamic alternative to physical solutions.

The current research assumes that dynamic solutions to passenger movement issues could be realised with better integration and control of lighting (e.g. using new LED based lighting, connected to Internet of Things control systems). The paper aims to offer a review of content from the literature and consultation with rail and transport related industry and lighting specialists, as part of a scenario-based approach to identify new concepts for innovative lighting in influencing passenger movement within train stations. The paper determines the current thinking in terms of research on lighting for this type of context, considering this in relation to the issues and experiences described by a wide range of aligned stakeholders. The added accessibility and applicability of the research findings from this study will be valuable to designers (lighting and infrastructure) and operational staff within rail and other transport or service industries.

\section{$2 \quad$ Literature Review}

Thirty six research papers and three review papers ${ }^{26-28}$ have been reviewed to explore how lighting principles can be used to influence movement behaviours in stations. The literature within the three review papers, compiled over a series of studies that explored the 
potential for use of innovative lighting in rail transport and retail situations, was used as a starting point. The source materials within these were identified using several research databases, including NUSEARCH (hosted at the University of Nottingham), Scopus, Web of Science and Google Scholar. Search terms included combinations of the light* and the following contextual terms - public space; crowd control, behaviour, wayfinding, accessibility, affordance; dynamic; smart; mood; affect; feeling; emotion; atmosphere; visual; colour. To determine the suitability for this study, abstracts were read to identify relevance to the study aims. To be included, the article needed to report on one or more characteristics of lighting or similar visual cues on aspects of behaviour, movements, performance or mood. The papers covered studies in laboratory situations, in virtual reality and real world studies. Further searches were carried out to look for recent publications, in particular how lighting might influence general wayfinding, crowd behaviour and the design of architectural spaces. ${ }^{29}$ These searches used similar keywords and the search terms linked to the main characteristics of lighting (e.g. intensity, colour, movement) that were emerging during the course of the review. Reference lists were searched and citation searches were conducted for selected papers. No dates were used to restrict the search for publications. The review focused primarily on the likely psychological/behavioural effects of lighting (as opposed to physiological), although as indicated earlier, there was a degree of overlap in how these have been considered and reported in previous work.

The review takes a diverse view of the literature, in order to appreciate how different characteristics of lighting can influence and impact behaviour, to establish particular lighting values (where specified) and clarify resultant behaviours. However, it is evident that the research literature in this area is not only dispersed, but also often emergent, making it somewhat difficult to identify relevant sources. This is clearly demonstrated by de Kort and Veitch ${ }^{9}$ who, following an initial search of The Journal of Environmental Psychology, as part of developing a special issue on light, lighting and behaviour, found "only 6 papers with 'light' or 'lighting' as a keyword; in contrast, 281 used 'noise' or 'sound". Findings can also be inconclusive or conflicting, a possible symptom of the complex relationship between light and effect. ${ }^{30}$ This complexity has been further compounded by the multifaceted nature of many lighting studies, which often include multiple lighting characteristics in different combinations, examined in relation to a diversity of outcomes (e.g. improved path detection through to increases in product buying) and within a range of contexts. In order to provide some clarity, this review is organised according to five key characteristics of lighting that have been identified from the literature: intensity; colour; flicker/flash rate; 
position/direction; source/operation. Whilst there are potential overlaps, these characteristics offer useful qualities that can be referred to and potentially applied in the development of innovative, lighting installations within a transport context. Appendix 1 provides brief summaries of the key literature referred to in eliciting these lighting characteristics.

\subsection{Lighting characteristics and behavioural effects}

\subsubsection{Intensity}

Changing the intensity of lighting may influence the speed and choice of movement e.g. direction/route and also the mood or subjective well-being of people. Pedersen and Johansson ${ }^{19}$ examined the effects of reduced lighting levels upon walking speeds, reporting that participants walked significantly slower under dimmed $(60 \%, 40 \%$ and $20 \%$ of maximum illuminance) lab-based, street lighting, and the effect continued when such levels were increased back to $100 \%$. People may be hesitant under reduced visibility, but also display generalised uncertainty in response to varying lighting levels. Contradictory results have however been produced, where darker pathways induce quicker walking speeds ${ }^{31}$ and have a significant impact upon the decision to walk, ${ }^{32}$ both of which can be largely attributed to reduced perceptions of personal safety. Furthermore, increases in sensation seeking have been observed under lower compared to higher illuminance. ${ }^{33}$ Nevertheless, in station environments, where rushing and running are concerns, the use of lower lighting levels to induce slower walking speeds could be considered, although a minimum overall lighting level must be maintained for overall safety and performance (e.g. legibility of signage).

Increasing lighting levels in defined spaces (e.g. entrances to alternative tunnels /corridors), can impact on wayfinding and route selection. In navigation studies in virtual environments (e.g. an emergency evacuation scenario ${ }^{21}$ and a hotel ${ }^{22}$ ), although signage was generally found to be the strongest indicator of choice, a brighter, narrower (as opposed to a darker, wider) corridor was typically chosen by participants: a brighter, wider corridor (1.5 m optimum), afforded $100 \%$ selection. ${ }^{21}$ Within a train station context, this effect could be applied to encourage choice of an alternative or optimised route.

Changes in lighting levels have also been shown to support improvements in mood and subjective well-being by mimicking the effects of day-light, inducing levels of natural activation and relaxation. ${ }^{34}$ Leppämäki et $a l^{35}$ reported on the benefits to (female) shift workers of brief, bright exposures to light (2500-4000 lx), combined with exercise. Hoffmann et $a l^{20}$ found that subjective mood could be improved in an office environment by constantly (over a 30 minute period), but imperceptibly changing illuminance (500 - 1800 lx) and 
Correlated Colour Temperature (CCT) (4000 - 6500 k). Varying lighting levels in this way, over shorter periods or across a working day, could potentially benefit passengers having to wait for extended periods.

\subsubsection{Colour}

Colour within lighting broadly relates to either warmer or cooler white light, indicated by its CCT or specific colour hues, existing as pure monochromatic wavelengths or created by combining different wavelengths of light. As mentioned previously, there is a potential to influence activity levels and mood through differences in CCT. ${ }^{20}$ Warm, white light (2700 k) is generally reported as more relaxing, approachable and pleasurable and as such often used in retail environments. ${ }^{36}$ Alternatively, neutral CCT (4000 k) is preferable for orientation and wayfinding tasks, ${ }^{37}$ whereas cool white light (5000 k) can support more attentive, focused behaviours. However, in a major study on the influence of warm, cool and artificial daylight lighting on self-reported mood and cognitive performance, there was no direct effect found of warm lighting on mood, though participants performed better in terms of short-term memory and problem solving. ${ }^{38}$ Moreover, a warm CCT was found to increase levels of hostility compared to cool CCT. ${ }^{33}$ Whilst there is certainly potential to use CCT to create more relaxing versus engaging spaces within a station (e.g. ticket halls), further evidence is needed.

Changes in hue have also been widely examined. Elliot $e t a l^{39}$ explained the notion of paired associations i.e. "both explicit and subtle pairings between colours and particular messages, concepts and experiences" (p. 155), which develop from infancy and directly influence affect, cognition and behaviours (e.g. red writing on research materials evoked avoidance motivation thus undermining performance on achievement tasks ${ }^{39}$ ). However, understanding the meanings that people from different cultures attach to particular coloured lighting, in particular contexts, is crucial in exploiting these colours effectively. Red lighting is thought to be more activating leading to impulsive behaviour, ${ }^{40}$ aligning with its effectiveness in hazard warning signals ${ }^{41}$ (see below). Green lighting (which is suggested to be less anxiety provoking than red illumination ${ }^{42}$ ) has also been studied in relation to emergency egress, showing the positive effects of green, floor level LED track lighting upon walking speeds and movement paths in a VR-based rail tunnel evacuation. ${ }^{18}$ Green (or white) flashing lights performed better than blue in promoting emergency exit usage. ${ }^{17}$ Barlı et $\mathrm{al}^{43}$ demonstrated the positive impact of green lighting upon time spent in a retail store and subsequent increased product purchases. The effects of pulsating orange light as a distractor in stress recovery were inconclusive. ${ }^{44}$ Finally, blue lighting has afforded considerable 
interest in recent years, for its alleged positive role in suicide prevention at rail stations ${ }^{14,15}$ (though this was questioned by Ichikawa et $\mathrm{l}^{16}$ ). Blue is often described or associated with being a calming colour, ${ }^{11,} 42$ although its effect upon the circadian system of supressing the production of the hormone melatonin is likely to induce a more active, engaged and aware state over longer periods. ${ }^{45}$ Chellappa et $a l^{46}$ have reported enhanced subjective alertness, well-being and faster reaction times in tasks requiring sustained attention in a cool, white, blue-shifted light (40 lx, $6500 \mathrm{~K})$.

The use of coloured lighting within train stations to enhance passengers' levels of awareness, to support changes in mood or to influence the direction of movement has obvious potential. However, at a practical level, careful consideration is needed so as not to conflict with existing use of coloured light signals in rail operations.

\subsubsection{Flicker/flash rate}

Flicker/flash rate is typically examined in conjunction with intensity and/or colour. Indeed, flash rates (where the pulse duration is less than the inter pulse interval length ${ }^{47}$ ) have been widely researched in relation to emergency and safety contexts. Although values can vary, an optimum flash rate of $1-4 \mathrm{~Hz}$ is considered most effective in emergency exits ${ }^{17}$ and a rate of $240 \mathrm{fpm}(4 \mathrm{~Hz})$ for conveying a sense of hazard. ${ }^{41}$ Whilst flashing could be effective in the current context for attracting or directing attention and influencing movement, it would be important not to conflict with existing emergency lighting and should also be considered in conjunction with other modes of communication, e.g. audio messages and alerts.

Flicker can also be used to induce positive effects in behaviour, such as heightened levels of activation when exposed to a high and imperceptible flicker rate of $32,000 \mathrm{~Hz}{ }^{48}$ However, there are also some notable, negative health impacts of flicker. These include headaches and impaired vision from longer exposures to invisible flicker (typically below $165 \mathrm{~Hz}$ ), through to photosensitive epileptic seizures incurred from brief exposures to visible flicker - typically between 3-70 Hz, although the greatest risk being between $15-20 \mathrm{~Hz}{ }^{2}$ Flicker can also have a significant and often detrimental effect on those with sensory sensitives and neurodevelopmental conditions such as autism, with bright or flickering lights often being painful ${ }^{49}$ and potentially exacerbating repetitive behaviours. ${ }^{50}$ Therefore, whilst a high, undetectable flicker rate could be effective in supporting levels of activation and awareness on a platform, rates need to be designed carefully and monitored to avoid any detrimental effects. 
Linearly configured, sequential flashes can be used to indicate movement or direction. Cosma et $a l^{18}$ examined the use of continuous versus chasing (green) LED track lighting to support emergency egress, and whilst little significant difference was found between the two upon walking times, in comparison with no lighting intervention, participants tended to walk closer to the lights. In the absence of further research, it may still be useful to consider the use of chasing or travelling lights to indicate directional paths, particularly as such lights are increasingly used in other contexts (e.g. lane closures on highways).

\subsubsection{Position/direction}

Arrow-like lights influenced crowd decision making when walking through a walkway with a central obstacle, resulting in $27 \%$ more pedestrians selecting the indicated side than the non-indicated side of the obstacle. ${ }^{13}$ Floor-mounted lighting tracks were also found to guide movement paths ${ }^{18}$. Wright et al ${ }^{51}$ reported wall-mounted lighting tracks (1000 $\mathrm{mm}$ above floor level), induced quicker walking speeds than standard high mounted emergency lighting. Conversely, for older people walking along dimly lit corridors, ceiling mounted lights offering diffuse illuminance (as opposed to plug-in night lights or night lights with path edge lighting), best supported walking speeds and gait. This said, edge lighting did contribute to supporting movement paths by offering laser lines to follow. ${ }^{52}$

The directionality of lighting is key within retail, particularly when combined with intensity and colour, to direct and maintain attention. ${ }^{53}$ Overall, despite limited guidance on specific or optimum effects, the position and direction of lighting is crucial for maintaining overall visual acuity and performance levels, whilst also creating a focus. Moreover, the physical environment in which lighting is situated also plays a crucial role in influencing people's understanding and perception of a space and subsequent engagement with it, i.e. naturally affording certain behaviours. ${ }^{54}$ Indeed, in a study of emergency egress from a labbased, smoke filled tunnel, ${ }^{55} 91 \%$ of participants were reported to navigate using the physical walls (in addition to lit exit signs), for $75 \%$ of the $200 \mathrm{~m}$ distance.

\subsubsection{Source/operation}

There have been several studies on the impact upon mood and performance of individuals having control of the lighting in their workplace. LED lighting offers increased efficiencies, a variety of visual effects and greater control in relation to more traditional lighting technologies. ${ }^{10}$ Veitch and Newsham ${ }^{56}$ found no significant improvements in mood or performance with additional control, whilst Moore $e t a l^{12}$ concluded that although people 
preferred to have more influence, offices without such controls were more effectively lit (in terms of task illuminance/luminance levels). Despite such ambivalent results, lighting that is felt by passengers to be more directly responsive to their actions and the changing situation within a station, could offer a more meaningful and engaging experience. Indeed, there is a growing body of research into the impact of interactive lighting installations in public, urban spaces e.g. ${ }^{57,58}$ which suggest responses and feedback that are perceived to map directly to our actions, encourage our overall sense of engagement, empowerment and agency. ${ }^{59}$

\subsection{Conclusions from the literature}

The relationship between light and behavioural effect is complex, ${ }^{30}$ with research in the area sometimes being contradictory and inconclusive, making it difficult to generalise to wider contexts. Indeed, specifying a definitive set of lighting variables that can be applied to affect a particular behaviour or response in a situation may be challenging. However, using the five lighting characteristics as a working guide for researchers and lighting designers, it is possible to distinguish effects that could potentially translate to the rail context. A stakeholder engagement activity was carried out to establish the specific industry-based, behavioural and operational contexts which might be relevant to the implementation of lighting-based interventions.

\section{Methods}

An investigation was carried out into the potential effects of different characteristics of lighting on behaviours, and the extent to which these might be employed to address problematic behaviours in train stations. This section outlines the methods applied in consulting with a wide range of rail and lighting stakeholders, to identify, contextualise and prioritise current issues and problematic behaviours associated with passenger movements in train stations. Insights from the literature review and subsequent stakeholder consultation activities are then combined, leading to the identification of a series of key scenarios to guide and inform the development of innovative lighting within train stations.

\subsection{Stakeholder consultation}

Specific engagement activities (interviews, a workshop and site visits) were carried out with 25 rail and transport related stakeholders, with a diversity of roles/backgrounds including station managers, safety and security officers, customer experience leads and building service engineers both from individual Train Operating Companies (TOCs) and 
Network Rail (NR), in addition to academics in transport/user-research and an officer from the British Transport Police (BTP). These activities were designed to draw upon the expert knowledge and experience of stakeholders, to understand the issues that impact movement and passenger behaviour in train stations. The intention was to identify a range of examples of problematic locations and associated behaviours, identify existing interventions to minimise such problems and explore opportunities where innovative lighting might be applied in further addressing these issues. The overall approach (particularly towards the workshop and site visits) was collaborative, with rail/transport specialists interfacing with lighting technologists and academic researchers (Human Factors) and served to generate a body of primarily qualitative data.

\subsubsection{Stakeholder interviews}

Eighteen one-hour telephone interviews were first conducted, to identify stakeholders' experiences. Interviews included questioning relating to job role, associated duties and length of service, with a Critical Incident Technique ${ }^{60}$ used to elicit participants' personal experiences and observations of both more positive and also negative instances of movement in stations. Using this technique enabled participants to focus more directly on their own experiences, whilst also reflecting upon their relative meaning and significance. Participants were also asked to consider why, where and to what extent such movement-related problems occur and how these are currently being addressed, in conjunction with any potential barriers to success. Finally, participants were asked to imagine how lighting might be used to better manage passenger movement and behaviours, what this might look like and any potential issues that may arise in implementation. The interviews also served to frame topics for discussion in the second engagement activity i.e. a one-day workshop.

\subsubsection{Stakeholder workshop}

A one-day workshop was conducted involving twelve stakeholders (five of whom had participated in the telephone interviews). Each participant completed a questionnaire, similar in format to the interview, capturing their job role, better versus worse experiences of moving around train stations and also a ranking of their top three movement-related problems in these contexts. A group discussion was used to highlight significant movement related issues, and researchers recorded key points on a white board so that these were visible to all involved. Participants were then split into smaller groups (of three) and asked to consider the issues raised more specifically, using a set of pre-prepared resources. These included images (i.e. a 
station plan and photographs) of a sample station, which were used as visual prompts (i.e. ${ }^{61}$ ) to encourage participants to elaborate on movement issues commonly linked to a physical location or feature. Participants annotated the images with their thoughts and ideas. A series of general questions helped to guide the participants through this exercise, covering questions including 'what are the main contributors/causes of movement problems in a train station?', 'where should a new lighting product be located for maximum effectiveness?' and 'what are the risks associated with such innovative lighting?' This activity was followed by a presentation of potential lighting products and an explanation of different lighting characteristics (drawn from the literature review). Participants were then requested to reappraise their annotated images from the earlier activity in light of this information. Finally, participants were asked to re- rank their top three movement-related problems, taking account of the likely severity of the problem, the feasibility of implementing a lighting solution and the potential impact of a lighting solution. Rankings were discussed across the whole group and movement related problems subsequently prioritised in conjunction with potential recommendations for lighting solutions.

\subsubsection{Site visits}

Three site visits to a trial train station were conducted by both the researchers and lighting designers/technologists over a five month period (spring/summer), during peak and off-peak hours. The visits offered the opportunity to take photographs of the infrastructure, and to envision how people might move around different parts of the station (e.g. entrance gates, stairways, bridges, walkways and platforms) and better understand the context of some of the key movement issues raised in the engagement activities. These visits also enabled identification of in situ opportunities for the use of innovative lighting to address these problems. The academic-researchers and designer-technologists were able to develop a situated, shared understanding of the issues and also begin to evolve a common language by which they could communicate as the project progressed.

\subsubsection{Data analysis synthesis}

The study activities served to produce a rich body of data. These included: outputs from the literature review; photographs from the site visits; and descriptive (textual) data from the various engagement activities (i.e. interviews, workshop and site visits), including researcher notes, questionnaire responses, annotated station plans/images and problem/solution ranking grids. These data were subsequently analysed in three key stages. 
First, a general review of the interview and questionnaire responses was undertaken and a number of generic issues were identified, broadly aligning to questioning relating to movement problems, existing solutions and lighting opportunities in train stations. A conventional content analysis ${ }^{62}$ was then applied to the data as a whole, i.e. including researcher and participant notes. This enabled categories to emerge and evolve directly and inductively from within the data. Indeed, through an iterative process of collating, comparing, coding/classifying and reflecting upon the data, an initial set of largely location-driven categories were developed. These included relevant location/physical feature, associated behavioural issue, solution required, and opportunities for lighting, with the latter category being directly supported by evidence derived from the literature review. However, during this process it became evident that whilst participants' insights and experiences were often intrinsic to their location, listed against each of these were a number of distinct yet commonly reoccurring behaviours (e.g. waiting, decision-making). The final stage of analysis therefore involved re-examining the data in relation to key behaviours, any of which could occur in a variety of locations at any one time (Table 1).

\section{Results}

A set of behaviourally-driven categories emerged including: observable problematic behaviours; required solution(s); and potential lighting opportunities (see Table 1). Based upon these categories and through further guidance from the lighting technologists, a number of behaviourally-driven scenarios were then developed, which served to inform the subsequent development of the lighting-based interventions. These scenarios, based on theory (literature) and practice (stakeholder consultations and industry site visits) are outlined in Table 2 .

Combining the findings from both the literature review and the stakeholder engagement activities, enabled a number of proposals to evolve for how innovative lighting could be applied to influence particular movement and behaviours in a train station context. These proposals were further guided by advice from stakeholders (particularly lighting technologists) on the practicability/effectiveness of particular lighting within a particular scenario. The six scenarios and corresponding proposals for lighting interventions are detailed below (Table 2). 


\section{Discussion}

A review of the behaviourally-orientated lighting literature was initially conducted, which served to inform a series of engagement activities with transport (including rail) and lighting stakeholders, to elicit and understand current movement and behaviour related issues in train stations and existing approaches for addressing these. These activities offered a valuable knowledge base to identify generic lighting effects e.g. increasing the intensity of light in narrower versus wider corridors to influence route selection, ${ }^{21,22}$ that could be applied to influence potentially problematic passenger behaviours. The knowledge of typical behaviours in stations and the understanding of these lighting effects were then considered in the development of the particular scenarios and proposals for innovative lighting solutions that need to be evaluated in future studies. In this paper the potential to apply these effects has been considered in relation to a series of typical railway station settings, drawing on evidence from the literature and a series of consultation exercises with railway/lighting stakeholders. Such interventions have the potential to support movement behaviours in more intuitive, responsive and adaptive ways, whilst also avoiding another immutable layer of visual information and clutter from additional signage.

Although not specifically a focus of this paper, it would be useful to understand the benefits of lighting interventions over and above existing interventions, such as physical measures or increased staff support. It could be argued that the dynamic nature of many lighting products, along with their ability to convey a level of semantic meaning ${ }^{64}$ in a simplified manner (compared with, for instance, signage) provides some of these benefits. The lighting interventions discussed here can be applied with some flexibility (i.e. with the ability to reposition, dim, turn on/off as required) and in a non-intrusive way (situated largely overhead), integrating effectively within the many physical, operational and financial constraints of a station environment. Moreover, they do not add to the visual clutter that is already apparent in railway stations. For example, not knowing where to wait (see Scenarios 1 and 2), particularly on a platform prior to boarding a train, can cause blockages in flow, potential uncertainty or stress for passengers and increased boarding and alighting times. Using lighting that can adapt to different lengths and configurations of trains, to indicate where passengers should congregate for access to a particular carriage, would mitigate these issues and encourage better distribution of passengers along a platform, without the need for additional signage, staff intervention or audio announcements. Similarly, knowing which direction to take having alighted a train (see Scenario 3) can help to reduce blockages arising from uncertainty and indecision. Typically, wayfinding information is displayed as textual 
signs, which may exclude people who are unfamiliar with the language, cannot see the signage or, for whatever reason, cannot comprehend the signage. Using lighting to indicate the optimum route to stairs, lifts and exits can help passengers to disperse quickly from the platform and maintain a continuous flow, without reliance on passengers being able to read / interpret text. Moreover, bunching, blockages or rushing in confined spaces such as stairways and bridges (see Scenario 4) can have serious safety implications (e.g. slips, trips and falls) and cause stress and frustration to other passengers. Using responsive lighting to separate passengers in these areas (e.g. up/down; left/right and regulate flows and movement speeds), could help to reduce such dangers and conflicts, without the need for static, physical directions or for staff to direct passengers.

Whilst these scenarios offer a potentially practicable approach for introducing innovative lighting to address movement related issues in train stations, particularly in the absence of a clear consensus within the literature and few credible, real-world examples, there are certain limitations of the study which should be acknowledged. A search of the academic literature relating to lighting and behaviour has been conducted, though it is acknowledged that there is limited conclusive evidence from which to draw robust conclusions regarding the potential of lighting characteristics to affect behaviour. For this reason, well-considered, field-based evaluation studies of lighting interventions are needed to expand the body of knowledge in this area. Moreover, whilst a detailed review is outside of the scope of this paper, it is crucial to conduct an examination of evidence relating to crowd movements (e.g. ${ }^{65}$ ) and individual decision making within crowds (e.g. ${ }^{66}$ ), considering the particular ways in which people might respond to alternative lighting interventions in differing circumstances.

Developing a rigorous evaluation methodology that can be applied within the context of a real railway station is vital, but challenging. Existing frameworks for the evaluation of transport/rail safety interventions are available and can be adapted to fit the existing context. 25, 67 This will require the selection of an appropriate trial station, taking account of the platforms and stairways, the trains to study (type, configuration, timings, stopping positions), obtaining the required permissions and access, and identifying the hardware and software required to capture, store and analyse passenger movement data in an ethical and secure way, throughout the duration of the study.

Whilst the consultation workshop involved a diversity of key stakeholders, their insights may be limited to the participants' own experiences and preferences and potentially constrained by industry related policy and agendas. Wider consultation with a range of 
industry stakeholders, both within and outside the rail industry may provide additional views of the possibilities for new lighting interventions.

Finally, whilst the scenarios and proposals for lighting interventions identified through the study are potentially relevant in any train station context, there will be a need to ensure that they translate effectively to any given railway station setting.

\section{Conclusions}

The current study offers an approach to developing new concepts for lighting-based interventions. This approach is informed by a review of the available academic literature relating to the five characteristics of lighting identified and consultation with rail and transport stakeholders, along with lighting specialists, to consider how passengers' movements and behaviours can be influenced in train stations. Insights and guidance from the study offer an invaluable resource to designers, developers and operational staff within railways and also other transport/service-related industries where managing people movement is a factor. The identified scenarios provide researchers with a range of common, tangible, real-world movement related problems and potential solutions that need to be evaluated. Specifically, it is proposed that well-designed evaluations are conducted on the following and will be the focus of a subsequent study:

1) The use of zones of light to indicate optimal waiting positions for effective boarding/alighting.

2) The use of zones of in light in order to encourage dispersion along the length of the platform to alleviate crowding issues.

3) The use of zoning and bathing specific facilities in light in order to indicate optimum routes into/through/out of stations and trains.

4) The use of pulsing or chasing lights to determine bi-directionality in crowd movements plus overhead lighting to maintain task related functioning in crowds.

5) The use of pulsing or chasing of lights to indicate appropriate walking pace in different conditions.

6) Changes in properties to affect subjective mood/feelings of wellbeing and safety, as well as providing emergency assistance for wayfinding. 


\section{Acknowledgements}

The author(s) disclosed receipt of the following financial support for the research, authorship, and/or publication of this article: This work was supported by Innovate UK [grant number 103965].

\section{Declaration of Conflicting Interests}

DW Windsor have a financial interest in lighting products which may be developed based on the work described in this paper.

\section{References}

1. Boyce PR. Human factors in lighting. 3rd edition ed. Boca Raton: CRC Press, 2014.

2. Wilkins A, Veitch J, Lehman B. LED lighting flicker and potential health concerns: IEEE standard PAR1789 update. 2010 IEEE Energy Conversion Congress and Exposition (ECCE). Atlanta, GA, USA: IEEE, 2010, 171-178.

3. Waterson PE, Kendrick VL, Ryan B, Jun T, Haslam RA. Probing deeper into the risks of slips, trips and falls for an ageing rail passenger population: applying a systems approach. IET Intelligent Transport Systems 2016; 10: 25-31.

4. Health and Safety Executive H. Lighting at work. UK: Health and Safety Executive, HSE, 1997.

5. The Society of Light and Lighting. Lighting Guide 15: Transport Buildings -Lighting for the built environment. London, UK: The Lavenham Press, 2017.

6. So ATP, Leung LM. Indoor lighting design incorporating human psychology. Architectural Science Review 1998; 41: 113-24.

7. Manav B, Yener C. Effects of different lighting arrangements on space perception. Architectural Science Review 1999; 42: 43-7.

8. Figueiro MG, Rea MS. Vision and Lighting. In: Hedge A, (ed.). Ergonomic workplace design for health, wellness, and productivity. CRC Press, 2016.

9. de Kort YA, Veitch JA. From blind spot into the spotlight. Journal of Environmental Psychology 2014; 39: 1-4.

10. Quartier K, Vanrie J, Van Cleempoel K. As real as it gets: What role does lighting have on consumer's perception of atmosphere, emotions and behaviour? Journal of Environmental Psychology 2014; 39: 32-9.

11. Dalke H, Little J, Niemann E, Camgoz N, Steadman G, Hill S, Stott L. Colour and lighting in hospital design. Optics \& Laser Technology 2006; 38: 343-65. 
12. Moore T, Carter DJ, Slater AI. A study of opinion in offices with and without user controlled lighting. Lighting Research \& Technology 2004; 36: 131-44.

13. Corbetta A, Kroneman W, Donners M, Haans A, Ross P, Trouwborst M, Van de Wijdeven S, Hultermans M, Sekulovski D, van der Heijden F. A large-scale real-life crowd steering experiment via arrow-like stimuli. 9th International Conference on Pedestrian and Evacuation Dynamics. Lund, Sweden2018.

14. Matsubayashi T, Sawada Y, Ueda M. Does the installation of blue lights on train platforms prevent suicide? A before-and-after observational study from Japan. Journal of Affective Disorders.2013; 147: 385-8.

15. Matsubayashi T, Sawada Y, Ueda M. Does the installation of blue Lights on train platforms shift suicide to another station?: Evidence from Japan. Journal of Affective Disorders 2014; 169: 57-60.

16. Ichikawa M, Inada H, Kumeji M. Reconsidering the effects of blue-light installation for prevention of railway suicides. Journal of Affective Disorders 2014; 152: 183-5.

17. Ronchi E, Nilsson D, Kojić S, Eriksson J, Lovreglio R, Modig H, Walter AL. A virtual reality experiment on flashing lights at emergency exit portals for road tunnel evacuation. Fire Technology 2016; 52: 623-47.

18. Cosma G, Ronchi E, Nilsson D. Way-finding lighting systems for rail tunnel evacuation: A virtual reality experiment with Oculus Rift ${ }^{\circledR}$. Journal of Transportation Safety \& Security 2016; 8: 101-17.

19. Pedersen E, Johansson M. Dynamic pedestrian lighting: Effects on walking speed, legibility and environmental perception. Lighting Research \& Technology 2018; 50: 522-36.

20. Hoffmann G, Gufler V, Griesmacher A, Bartenbach C, Canazei M, Staggl S, Schobersberger W. Effects of variable lighting intensities and colour temperatures on sulphatoxymelatonin and subjective mood in an experimental office workplace. Applied Ergonomics 2008; 39: 719-28.

21. Vilar E, Teixeira L, Rebelo F, Noriega P, Teles J. Using environmental affordances to direct people natural movement indoors. Work 2012; 41: 1149-56.

22. Vilar E, Rebelo F, Noriega P, Teles J, Mayhorn C. Signage versus environmental affordances: is the explicit information strong enough to guide human behavior during a wayfinding task? Human Factors and Ergonomics in Manufacturing \& Service Industries 2015; 25: 439-52.

23. RSSB. Rail Technical Strategy Capability Delivery Plan. In: Rail Safety and Standards Board R, Rail Delivery Group R, Rail Supply Group R and Network Rail N, (eds.). UK: Rail Safety and Standards Board, RSSB, 2017.

24. Ryan B, Kallberg V-P, Rådbo H, Havârneanu GM, Silla A, Lukaschek K, Burkhardt JM, Bruyelle J-L, El-Koursi E-M, Beurskens E. Collecting evidence from distributed sources to evaluate railway suicide and trespass prevention measures. Ergonomics 2018; 61: 1-21. 
25. Ryan B, Wronska U, Stevens I. Evaluating rail suicide prevention measures. Rail Human Factors London, 2017.

26. Topliss B. Lighting's effect on emotion, mood and affect. Masters thesis. Human Factors Research Group. UK: The University of Nottingham, 2017.

27. Cundell C. Influencing behaviour through lighting design in indoor spaces. Masters thesis. Human Factors Research Group. UK: The University of Nottingham, 2017.

28. Grant S. Influencing consumer behaviour through the use of multisensory atmospherics in retail spaces. Masters thesis. Human Factors Research Group. UK: The University of Nottingham, 2017.

29. Mansfield KP. Architectural lighting design: A research review over 50 years. Lighting Research \& Technology 2018; 50: 80-97.

30. Limpens Y. Portraying stress in a positive light. Masters thesis. Human Technology Interaction. Netherlands: Eindhoven University, 2012.

31. Donker S, Kruisheer J, Kooi F. Pedestrian walking speed as a tool to study environment-behavior. 9th Biennial Conference on Environmental Psychology. Eindhoven University of Technology2011.

32. Fotios S, Gibbons R. Road lighting research for drivers and pedestrians: The basis of luminance and illuminance recommendations. Lighting Research \& Technology 2018; 50: $154-86$.

33. McCloughan C, Aspinall P, Webb R. The impact of lighting on mood. International Journal of Lighting Research and Technology 1999; 31: 81-8.

34. van Bommel W. Dynamic Lighting at work-Both in level and colour. 2nd CIE Expert Symposium on Lighting and Health 2006, p. 62-7.

35. Leppämäki S, Partonen T, Piiroinen P, Haukka J, Lönnqvist J. Timed bright-light exposure and complaints related to shift work among women. Scandinavian Journal of Work, Environment \& Health 2003; 29: 22-6.

36. Park NK, Farr CA. The effects of lighting on consumers' emotions and behavioral intentions in a retail environment: A cross-cultural comparison. Journal of Interior Design 2007; 33: 17-32.

37. Hidayetoglu ML, Yildirim K, Akalin A. The effects of color and light on indoor wayfinding and the evaluation of the perceived environment. Journal of Environmental Psychology 2012; 32: 50-8.

38. Knez I. Effects of colour of light on nonvisual psychological processes. Journal of Environmental Psychology 2001; 21: 201-8.

39. Elliot AJ, Maier MA, Moller AC, Friedman R, Meinhardt J. Color and psychological functioning: The effect of red on performance attainment. Journal of Experimental Psychology: General 2007; 136: 154. 
40. Crowley AE. The two-dimensional impact of color on shopping. Marketing Letters 1993; 4: 59-69.

41. Chan $\mathrm{AH}, \mathrm{Ng} \mathrm{AW}$. Perceptions of implied hazard for visual and auditory alerting signals. Safety Science 2009; 47: 346-52.

42. Jacobs KW, Suess JF. Effects of four psychological primary colors on anxiety state. Perceptual and Motor Skills 1975; 41: 207-10.

43. Barlı Ö, Aktan M, Bilgili B, Dane Ş. Lighting, indoor color, buying behavior and time spent in a store. Color Research \& Application 2012; 37: 465-8.

44. Wan SH. An explorative study about the effect of pulsating lighting on stress-recovery. Human Technology Interaction. Netherlands: Eindhoven University of Technology, 2011.

45. Lehrl S, Gerstmeyer K, Jacob J, Frieling H, Henkel A, Meyrer R, Wiltfang J, Kornhuber J, Bleich S. Blue light improves cognitive performance. Journal of Neural Transmission 2007; 114: 457-60.

46. Chellappa SL, Steiner R, Blattner P, Oelhafen P, Götz T, Cajochen C. Non-visual effects of light on melatonin, alertness and cognitive performance: can blue-enriched light keep us alert? PloS One 2011; 6: e16429.

47. Bartley SH, Nelson TM. A further study of pulse-to-cycle fraction and critical flicker frequency. A decisive theoretical test. Journal of the Optical Society of America 1961; 51: 41-5.

48. Knez I. Affective and cognitive reactions to subliminal flicker from fluorescent lighting. Consciousness and Cognition 2014; 26: 97-104.

49. Kinnealey M, Pfeiffer B, Miller J, Roan C, Shoener R, Ellner ML. Effect of classroom modification on attention and engagement of students with autism or dyspraxia. American Journal of Occupational Therapy 2012; 66: 511-9.

50. Kuller R, Laike T. The impact of flicker from fluorescent lighting on well-being, performance and physiological arousal. Ergonomics 1998; 41: 433-47.

51. Wright M, Cook G, Webber G. The effects of smoke on people's walking Speeds using overhead lighting and Wayguidance provision. Proceedings of the 2nd international symposium on human behaviour in fire MIT, Boston2001, p. 275-84.

52. Figueiro MG, Plitnick B, Rea MS, Gras LZ, Rea MS. Lighting and perceptual cues: effects on gait measures of older adults at high and low risk for falls. BMC Geriatrics 2011; 11: 49.

53. Summers TA, Hebert PR. Shedding some light on store atmospherics: influence of illumination on consumer behavior. Journal of Business Research 2001; 54: 145-50.

54. Gibson JJ. "The Theory Of Affordances": The Ecological Approach To Visual Perception. Boston, MA: Houghton Mifflin 1979. 
55. Fridolf K, Ronchi E, Nilsson D, Frantzich H. Movement speed and exit choice in smoke-filled rail tunnels. Fire Safety Journal 2013; 59: 8-21.

56. Veitch JA, Newsham GR. Exercised control, lighting choices, and energy use: An office simulation experiment. Journal of Environmental Psychology 2000; 20: 219-37.

57. Alwani R, Raby E, West J, Bichard J-A, Spencer J. Foyle Bubbles: How can design reduce suicide attempts using everyday social and civic spaces? In: Barron D and Seemann K, (eds.). Fourth International Conference on Design4Health 2017. Melbourne, Australia2018, p. 20-3.

58. Raby E, Alwani R, West J, Bichard J-A, Spencer J. Foyle Reeds: How can design reduce suicide attempts at a specific place whilst at the same time improving the experience for all? In: Barron D and Seemann K, (eds.). Fourth International Conference on Design4Health 2017. Melbourne, Australia2018, p. 219-22.

59. Hespanhol L, Tomitsch M. Strategies for intuitive interaction in public urban spaces. Interacting with Computers 2015; 27: 311-26.

60. Flanagan JC. The critical incident technique. Psychological Bulletin 1954; 51: 327.

61. Schock A, Ryan B, Wilson J, Clarke T, Sharples S. Visual scenario analysis: understanding human factors of planning in rail engineering. Production Planning and Control 2010; 21: 386-98.

62. Hsieh H-F, Shannon SE. Three approaches to qualitative content analysis. Qualitative Health Research 2005; 15: 1277-88.

63. Milliman RE. Using background music to affect the behavior of supermarket shoppers. The Journal of Marketing 1982; 46: 86-91.

64. Schielke T. The language of lighting: applying semiotics in the evaluation of lighting design. Leukos 2019; 15: 227-48.

65. Zhang Q, Han B, Li D. Modeling and simulation of passenger alighting and boarding movement in Beijing metro stations. Transportation Research Part C: Emerging Technologies 2008; 16: 635-49.

66. Moussaïd M, Helbing D, Theraulaz G. How simple rules determine pedestrian behavior and crowd disasters. Proceedings of the National Academy of Sciences 2011; 108: 6884-8.

67. Hills D, Junge K. Guidance For Transport Impact Evaluations. The Tavistock Institute, London, 2010. 
Appendix 1 - Summary of key literature as the basis for the study framework based upon 5 lighting characteristics

\begin{tabular}{|c|c|c|c|}
\hline Source & Method of study & Purpose of study & Summary details/key lighting characteristics \\
\hline $\begin{array}{l}\text { Barli, O., et al. } \\
(2012) 43\end{array}$ & $\begin{array}{l}\text { Real context (shopping } \\
\text { mall), over time } \\
\text { (weekend), multiple } \\
\text { participants (shoppers) }\end{array}$ & $\begin{array}{l}\text { To examine whether } \\
\text { interior colour/lighting } \\
(\mathrm{CCT}) \text { affects time } \\
\text { spent in a store and } \\
\text { product purchase }\end{array}$ & $\begin{array}{l}\text { Green interior colour and warm lighting }(\mathbf{C C T}) \text { were } \\
\text { positively associated with more time spent in a store and } \\
\text { increased product purchase }(\mathrm{s}) \text {. }\end{array}$ \\
\hline $\begin{array}{l}\text { Bartley, S.H. } \\
\text { and Nelson, } \\
\text { T.M. }(1961)\end{array}$ & $\begin{array}{l}\text { Lab-based, experimental, } 5 \\
\text { participants (including } \\
\text { authors) }\end{array}$ & $\begin{array}{l}\text { To examine the effect } \\
\text { of differing pulse } \\
\text { lengths upon flicker }\end{array}$ & $\begin{array}{l}\text { Shorter light pulses delivered in a repetitive cycle produce } \\
\text { flicker and when lengthened produce fusion (i.e. a steady } \\
\text { state/continuous light), although lengthening further can } \\
\text { induce a physiological response whereby the eyes 'off- } \\
\text { response' is reactivated i.e. flicker. }\end{array}$ \\
\hline $\begin{array}{l}\text { Chan, A. and } \\
\text { Ng, A. (2009) }\end{array}$ & $\begin{array}{l}\text { Lab-based, experimental, } \\
\text { multiple variables ( } 3 \\
\text { lighting colours, } 4 \text { flash } \\
\text { rates, } 3 \text { flash modes), } 144 \\
\text { test conditions, } 23 \\
\text { participants }\end{array}$ & $\begin{array}{l}\text { To examine optimum } \\
\text { visual (colour, flash } \\
\text { rate, flash mode) and } \\
\text { auditory signals in } \\
\text { hazard warning }\end{array}$ & $\begin{array}{l}\text { Red (flashing light) was the most effective warning colour; } \\
240 \mathrm{fpm} \text { the optimum flash rate and double/triple mode } \\
\text { further increases effectiveness. Blue and yellow lights were } \\
\text { less effective, but when combined with an auditory alarm } \\
\text { conveyed the same level of hazard as red colour alone. }\end{array}$ \\
\hline $\begin{array}{l}\text { Chellappa, S.L., } \\
\text { et al. (2011) } 46\end{array}$ & $\begin{array}{l}\text { Lab-based, experimental, } \\
\text { multiple variables ( } 2 \text { types } \\
\text { of lamp, } 3 \text { CCT colours at } \\
40 \text { lux }), 16 \text { male } \\
\text { participants }\end{array}$ & $\begin{array}{l}\text { To examine the effects } \\
\text { of CCT on cognitive } \\
\text { performance }\end{array}$ & $\begin{array}{l}\text { Exposure to cool-white, blue-shifted light i.e. } 40 \text { lux } \\
\text { (intensity) and 6500k colour temperature (CCT), supresses } \\
\text { melatonin and induces increased cognitive performance, } \\
\text { subjective alertness, well-being and visual comfort. }\end{array}$ \\
\hline $\begin{array}{l}\text { Corbetta, A,. et } \\
\text { al. }(2018)^{13}\end{array}$ & $\begin{array}{l}\text { Real context, (festival), } 4 \\
\text { conditions (left /right } \\
\text { arrow, double arrow and }\end{array}$ & $\begin{array}{l}\text { Examining the effects } \\
\text { of Moving Light } \\
\text { (arrow-like) targets on } \\
\text { the side chosen when }\end{array}$ & $\begin{array}{l}\text { Arrow cues resulted in higher pedestrian flows towards the } \\
\text { indicated route (position/direction), whether on the right or } \\
\text { left side of the obstacle. }\end{array}$ \\
\hline
\end{tabular}


no arrow), approx.140,000 participants.

Cosma, G., et al. Lab-based, Virtual Reality (2016) ${ }^{18}$

(VR), 3 lighting conditions (no light, chasing and continuous), 60

participants

Crowley, A.E. (1993) 40

Lab-based, experimental, 4 colour conditions (blue, green, yellow, red), 100 female participants

navigating an obstacle within a walkway.

To examine if dynamic (continuous $\mathrm{V}$ chasing), green, LED floor mounted lighting can support emergency egress

To examine the effects of interior colour on consumer responses/shoppers

Dalke, H., et al. Real context (hospital), 20 (2006) ${ }^{11}$ hospitals visited +
stakeholder engagement activities

Donker, S.F., et al (2011) 31

Elliot, A.J., et al $(2007)^{39}$ To examine optimum interior colours for use in a hospital

To examine the effects of street lighting on walking speed
Real context (street), 3 lighting conditions (daylight, evening + streetlights, evening + no streetlights), multiple participants (pedestrians)

Lab-based, experimenta
colour conditions (red, green, black/neutral), 71 participants
Green (colour), LED floor-mounted (position) strip lights have a positive effect on wayfinding in a smoke filled railway tunnel evacuation and whilst participants tended to walk closer to the lights, no significant difference was found between chasing and continuous lights (flicker/flash rate).

Within a shopping context, activating colours such as red (longer wavelength) may induce more impulse buying, whereas blue (shorter wavelength) incurs more evaluative responses, (but can also be activating). Green (mid wavelength) supports less activated/stable behaviours e.g. queuing to pay.

The use of interior colour schemes and levels of lighting

(intensity) is seen to have a significant impact on patients' and staff health and well-being. General guidance given, few specifics, although study notes that whilst blues and greens are typically seen as calming, they can exacerbate depression in mental health environments. Dim lighting and adaption are cited as issues particularly for the elderly and visually impaired.

A decrease in street lighting (intensity) increases walking speed, in comparison with the same street in daylight or in the evening with street lighting and is attributed to feelings of fear/anxiety, although further studies are suggested.

Red (colour) is seen to impair performance on achievement tasks due to its association with failure in achievement contexts and contributes to avoidance motivation. Brief relationship between

the colour red and

performance attainment 
Figueriro, M., et Lab-based, experimental, 3 To examine the effect al. $(2011)^{52}$

Fotios, S. and Gibbons, R. $(2018)^{32}$

Fridolf, K., et al (2013) ${ }^{55}$

Hespanhol, L. and Tomitsch, M. (2015) ${ }^{59}$

Hidayetoglu, M.L. et al. $(2012)^{37}$ lighting conditions (ceiling mounted, plug-in night lights, plug-ins + lighting lines), 24 older participants

Desk-top, literature based study

Real context (disused tunnel), study conducted with individual participants (100 in total)

Desk-top, literature based study

Lab-based, VR (indoor corridors), multiple variables (3 interior colours, 3 illuminance levels, 3 CCT values), 100 participants (students) perceptual cues on in older adults

To examine/review current standards for recommended road lighting To examine movement speeds and exit choice in (smoke filled), rail tunnels

\section{To develop a}

classification for intuitive interfaces within public/urban spaces

To examine the effects of colour and lighting levels on indoor exposure to red prior to an important task impairs participants' performance, often unconsciously.

Participants performed best (steady speed/gait) under ceiling mounted lights (position), night-lights (source) alone were least effective, although the addition of perceptual cues walking speeds and gait

(lighting lines) helped define the horizontal walking plane (direction) and could potentially reduce falls. wayfinding
Proposes the need for an effective standard for road lighting (intensity), based upon more empirical evidence i.e. to support improved visibility, improved safety and feelings of safety for drivers and pedestrians alike.

Illuminated, wall-mounted emergency signs depicting distances to the emergency exit (position/direction) had a positive effect on emergency egress, with a significant number of participants $(91 \%)$ also using the physical walls to navigate.

A framework for examining/developing intuitive interfaces and the means of operation/control or agency experienced, based upon the number of people interacting at any one time, the immediacy and focus of the feedback.

Warm interior colours (red) facilitated recall and orientation, although cool colours (blue) also aided navigation. Increased lighting levels (intensity) was perceived more positively and particularly by women. Neutral CCT (colour) was preferred in supporting wayfinding and orientation tasks. 
Hoffmann, G. et al. (2008) ${ }^{20}$

Real context (office), 1 control/1 test office, multiple variables (illuminance levels and CCT)

Ichikawa, M., et Desk-top, review of al. (2014) ${ }^{16}$ Governmental data

Knez, I. (2001)

Knez, I. (2014)

Lehrl, S., et al (2007) ${ }^{45}$ colours at 500 lux, 2 genders), 54 female/54 male participants (students) multiple variables (2 at $500 \operatorname{lux}), 132$ participants theatre), 4 colour
To examine the effects of variable lighting levels and CCT on the subjective mood of office workers

To qualify previous studies on the use of blue lighting in suicide prevention at railway stations

Lab-based, experimental, multiple variables (3 CCT

Lab-based, experimental, flicker frequencies, 3 types of lamp + 3 CCT colours

Simulated context (lecture conditions (room light, yellow, blue, white), 44 participants of blue light upon

cognitive performance affective and cognitive 列 flicker

To examine the effect
Varying the intensity and CCT (colour)

gradually/imperceptibly i.e. between the control office (500 lux, 400k) and the test office (500-1800 lux, 6500k), had a positive effect upon subjective mood and well-being and thereby potentially upon performance.

Based upon all railway suicide attempts listed in Japan between April 2002 and March 2012, of the 2535 (43\%) attempts within station premises, only $32 \%$ occurred at night and $28 \%$ at most at the end of platforms and at night. Blue coloured lights at the end of platforms (position) may have some effect upon preventing suicide, but the impact is likely to be smaller than has been otherwise reported.

Short term memory and problem solving was positively affected by warmer coloured lighting (as opposed to cool/artificial daylight), although no impact on mood was reported. Females' perception of the room light, across all CCT conditions, was more expressive/accentuated than for the men. Further studies are required to confirm.

High (as opposed to low) frequency/non visual flickering light had a positive impact upon cognitive processing and problem solving and was felt to be more pleasant. There was no significant effect from lighting colour (CCT).

Increased alertness combined with enhanced speeds of information processing (cognitive performance) were reported after exposure to blue coloured light, as opposed to yellow. 
Leppamaki, S et al. (2003) ${ }^{35}$

Manav, B. and Yener, $\mathrm{C}$. $(1999)^{7}$

Matsubayashi, T., et al. (2013)

Matsubayashi, T., et al. (2014) 15
Real context (hospital), 2 lighting conditions (normal and bright, 5000 lux), 87 female participants (nurses)

Lab-based, experimental, 4 lighting conditions (cove lighting, wall washing, up lighting, existing lighting), study conducted with individual

participants/students (174 total)

Desk-top, review of (Japanese) railway company data

Desk-top, review of (Japanese) railway company data
To examine the effect of brief, exposures to increased illuminance levels upon the subjective well-being of night-shift nurses

To examine the effects of different lighting arrangements on space perception

To examine the effects of blue lighting in suicide prevention at railway stations/train platforms

To examine whether the use of blue lighting in suicide prevention at train stations serves to shift these behaviours to other stations
Short periods ( 4 x 20 minutes) of increased brightness

(intensity) delivered over a night shift improved participants subjective well-being during and after a shift and

independently of season (summer/winter), or age.

Different lighting arrangements (position/direction) affect space perceptions, with wall washing giving impressions of clarity and order, cove lighting enhancing spaciousness and order and up lighting giving a relaxed, private and pleasant feel. In addition to arrangement, lamp types differed (source), as did CCT and Colour Rendering Index.

Suicide data from 71 Japanese train stations between 2000 2010 ( 11 with blue colour lighting/60 without) is examined before and after installation with an $84 \%$ reduction in suicides reported. These results are reported with several caveats e.g. data is based on a single railway company, blue lights vary in type, location and number across stations etc.

The number of suicides before and after the installation of blue colour lights at 14 stations and at 5 neighbouring stations on the same rail line was examined, to gauge possible substitution phenomenon i.e. people at risk seeking to take their life at other stations (without blue lighting). Results report $74 \%$ reduction in suicides and no systematic substitution at neighbouring stations. Again, limitations of the study are raised e.g. generalisability etc. 
McCloughan,

C., et al (1999)

33

Lab-based, experimental, multiple variables: 2 illuminance levels, 2 CCT levels, 64 participants.

Measures of affect in each condition.

Milliman, R.E. Real context (shopping (1982) ${ }^{63}$ Moore, 12

Park, N.K. and Farr, C.A. (2007) ${ }^{36}$

(no music, slow tempo music, fast tempo music), 9 week study duration, multiple participants (shoppers)

Real context (offices), 7 control offices/7 test offices, 2 lighting conditions (user controlled, centrally controlled), 352 participants

Lab-based, experimental, levels, 2 CRI levels, 2
To investigate mood effects under different illuminance/CCT levels, each of which might be encountered in conditions.

To examine the effect of background music (tempo) upon shoppers' behaviour multiple variables ( 2 CCT cultural groups), 98 participants (49 Caucasian American, 49 Korean)

To examine office workers' attitudes towards control of their office lighting levels

To examine the effect of lighting (colour quality) upon consumer emotions and

behavioural intentions across cultures everyday interior

There are initial effects of lighting on mood (sensation seeking is higher under lower illuminance within the first 5 minutes, hostility higher under warm CCT than cool), and longer term effects (sensation seeking was stable over 45 minute period, negative mood changes were complex and volatile over the study period).

Slower tempo music (associated with flash rates) can slow customer movement and thereby increase time in the shop and potential sales i.e. $38.2 \%$ increase in sales was reported during slower tempo (as opposed to fast tempo) music. Further studies are required to confirm.
Participants preferred the ability to control lighting levels (intensity) and reported improved lighting quality, even if centrally controlled conditions were objectively better (recommended task illuminance/luminance levels). User controlled lighting was also typically operated at $50 \%$ of maximum output, offering potential energy savings.

Lighting with a higher Colour Rendering index (CRI) and a lower CCT (warmer colour) is more pleasing to American customers, whereas Koreans were more inclined to enter a cooler lit interior. Cooler lighting (higher CCT) was noted as more beneficial when a focused state and visual clarity were required e.g. electronic and book stores, whereas warmer colours would support a more pleasurable experience e.g. gift boutique or spa shop. 
Pedersen, E. and Lab-based, experimental, 4 To examine the effect Johansson, $\mathrm{M}$ (2018) ${ }^{19}$ lighting conditions triggered by sensor $(20 \%$, $40 \%, 60 \%$ and $100 \%$ illuminance levels), study conducted with individual participants (61 total)

Quartier, K., et Simulated context (3 al. (2014) ${ }^{10}$ supermarkets representative of a high end, medium and budget), 3 lighting conditions (illuminance level/lux, spatial distribution, CCT), 95 participants

Ronchi, E., et al. Lab-based, VR (road (2015) ${ }^{17}$

tunnels), multiple variables (lighting colour, flash rate, type of light, number and layout of lights), 96 participants

So, A.T. and Leung, L.M. $(1998)^{6}$

of dynamic (sensor-

based/ responsive)

lighting upon walking

speed, legibility and

environmental

perception

To examine the impact

of lighting (in 3

representative

supermarket settings)

on atmosphere

perception, emotions

and consumer

behaviour

To examine the

optimum design of

flashing lights at

emergency exits to

support emergency

egress from road

tunnels

Desk-top, literature based study + a questionnaire, 120 participants
Participants walked significantly slower under dimmed lighting, even after the lighting levels (intensity) returned to $100 \%$, although little difference in speed was noted between dimmed conditions. Whilst legibility was reduced in dimmed lighting, this and overall perception were more affected by the overall lighting, as opposed to specific conditions.

Emotional responses and participants' perception of atmosphere was positively affected, even by subtle changes in lighting, particularly the use of warmer coloured lighting (CCT) and accent lighting (position). Effects upon consumer behaviour (e.g. increased product purchase) where not found to be significant, although participants tended to remain longer in the more favourable setting. Further studies are suggested.

Green or white coloured flashing lights performed better than blue, a flash rate of $1-4 \mathrm{~Hz}$ (as opposed to $0.25 \mathrm{~Hz}$ ) was recommended and LED type (source) performed better than single or double strobe lights. No significant differences were found in the 3 layouts/positions ( 2 bar lights either side of the emergency exit sign, 2 lights either side of the sign and 1 on top, 1 light above the sign).

94\% of participants felt more concentrated under a high illumination level (intensity), provided there was no glare, and $64 \%$ felt more relaxed under lower levels of illumination. Full results from the questionnaire are published in an Appendix and can be obtained from the author. human feelings,

behaviours and

performance 
Summers, T.A and Herbert, P.R. $(2001)^{53}$

Real context ( 2 shops hardware and animal supplies), supplemental lighting introduced over 2 product displays, behaviours video recorded, 2365 participants (shoppers)

van Bommel, W. (2006) ${ }^{34}$

Lab-based/simulated context?, multiple variables (illuminance level, CCT, duration), participants (number unspecified)

Veitch, J. A. and Simulated context (office), Newsham, G. R. 2 lighting conditions (1 (2000) ${ }^{56} \quad$ with lighting controls/1 without), 47 participants

Vilar, E., et al. $(2012)^{21}$

Wan, S. H. (2011) ${ }^{44}$ male/10 female)
To examine the impact of display lighting on 'customer approach avoidance' behaviours within retail

environments

To examine the effect of the level, colour and duration of lighting upon workers subjective health /wellbeing (including activation/ relaxation)

To examine whether individual control over lighting can improve (office workers) satisfaction, mood and/or performance

To examine people's preference, during emergency egress, for wider corridors,

brighter corridors or to naturally turn to the right

To examine the effect of orange pulsating light in reducing (orange/white light,
Customers spent more time at the displays with increased/supplemental lighting (intensity /direction), there was also an increase in the number of items touched and picked up. The authors acknowledge several limitations with the study i.e. no control over the particular items on display/near the display and the further studies are suggested.

Mimicking natural daylight within a workplace environment by adjusting the lighting level (intensity) and colour (CCT) over time, can improve workers natural levels of activation and relaxation.

Despite a general belief that greater control of the physical environment/lighting (intensity) improves workers health and well-being, no significant differences were found in satisfaction, mood or performance. Both groups indicated their preference for lighting levels (intensity) consistent with or lower than current recommended values. Further studies are suggested.

Participants preferred wider corridors and those with more lighting (intensity) and when the 2 variables were concurrent, afforded $100 \%$ selection. However, if one corridor is narrower but brighter than the other, which is wider and darker, people will select the former, suggesting lighting has greater influence. There was no significant difference in left/right turn preference.

Orange coloured, pulsating (flicker) lights $(0.125 \mathrm{~Hz})$ were found to have a partial effect on supporting stress recovery (with orange background light creating a more 'positive' 
static/pulsating light), 80 participants

Wilkins, A., et al. $(2010)^{2}$

Desk-top, literature based study Wright, M.S., et
al. (2001) stress/supporting relaxation in a hospital environment

To examine the health impacts relating to LED flicker, particularly for the power electronics/lamp designers

To examine the impact of different emergency lighting systems upon walking speeds atmosphere), however overall results were inconclusive. Further studies are suggested.

The biological effect of both visible $(3-70 \mathrm{~Hz})$ and invisible/imperceptible flicker (below $165 \mathrm{~Hz}$ ) are listed in relation to their specific source e.g. malfunctioning fluorescent lighting and frequency e.g. $50 \mathrm{~Hz}$

Traditional BS overhead (position) emergency lighting caused participants to walk significantly slower than the other way guidance lighting systems (electroluminescent/LED track), despite their reduced lighting levels (intensity). filled), 6 lighting conditions (including British Standard emergency lighting, normal overhead

fluorescent lighting, green electroluminescent wallmounted, track lighting and wall/floor mounted LED track lighting), 18 participants 
Table 1. Behaviourally-driven categories and potential solutions for addressing passenger movement and behaviour related issues

\begin{tabular}{|c|c|}
\hline Observable passenger behaviours and related issues & Potential solutions (including lighting opportunities) \\
\hline $\begin{array}{l}\text { 1. Capacity issues (general crowding) } \\
\text { 1.1. Crowding and obstruction of flow. } \\
\text { 1.2. Train dwell time caused by delays in passengers boarding } \\
\text { the train. } \\
\text { 1.3. Rapid build-up of people, which can happen after only 10- } \\
15 \text { minutes of disruption. } \\
\text { 1.4. Increase in the risk of accidents as a result of busy } \\
\text { stairs/escalators/gate lines/platforms etc. } \\
\text { 1.5. People entering the station when it is already full. } \\
\text { 1.6. Queuing/congestion at ticket machines and other points of } \\
\text { entry. } \\
\text { 1.7. Confusion, stress, aggression. }\end{array}$ & $\begin{array}{l}\text { 1. Capacity issues (general crowding) } \\
\text { 1.8. Managing overcrowding, crowd-control and encouraging } \\
\text { spread i.e. re-distributing, partitioning, regulating flow etc. } \\
\text { to ensure that crowds are dispersed, especially along the full } \\
\text { length of platforms. } \\
\text { 1.9. Identify designated waiting areas ensuring supporting } \\
\text { information is visible. } \\
\text { 1.10. Provide dynamic information about the status of a } \\
\text { facility i.e. to encourage dispersion/congregation to } \\
\text { optimum areas. For example: } \\
\text { - indicating which barriers are open and which are one- } \\
\text { way, } \\
\text { quickly attracting attention to open exits, } \\
\text { highlighting/counting down to the imminent arrival of } \\
\text { another train, } \\
\text { inform passengers about the capacity of the } \\
\text { station/area, } \\
\text { provide visual cues for alternative options elsewhere } \\
\text { e.g. direct people to other trains/replacement bus } \\
\text { service. } \\
\text { Make station/platform closures more salient and } \\
\text { responsive. } \\
\text { Facilitate egress or discourage passengers from } \\
\text { entering a crowded station/area. } \\
\text { Create an environment where people feel that } \\
\text { 1.11. }\end{array}$ \\
\hline
\end{tabular}




\section{Decision making}

2.1. Lack of understanding of the layout of station/platform, or of timetables/frequency of trains to same destination.

2.2. Confusion/indecision about which direction to take e.g. different platform numbers along the same platform.

2.3. Uncertainty/lack of knowledge of the best position to wait, or alternatively waiting in a strategic location in order to facilitate later processes e.g. commuters waiting in locations that are more conducive to their exit from the train at their destination.

2.4. Habit or prior knowledge might lead to choosing less optimal or incorrect routes.

2.5. Difficulty in wayfinding, e.g. dark platforms in underground stations, or distraction as a result of looking at phones rather than at wayfinding cues.

2.6. Need for information about surrounding area/community and how best to exit the station for their destination.

2.7. Influence of other members of a crowd.

2.8. Passengers walking the wrong way, or inadvertently going out of their way.

2.9. Increased stress levels.
2. Decision making

2.10. Complement or augment existing wayfinding cues to increase visibility and prominence within a crowd or from a distance.

2.11. Dynamic indicator to support passengers to find the best locations to wait for their train for optimum boarding and alighting, including displaying information relating to where passengers might be able to sit/where their reserved seat is.

2.12. Provide general wayfinding information linked to real-time information about train arrivals/departures.

2.13. Enhance existing (well-designed \& placed) signage and/or replace this with more 'intuitive' wayfinding in order to reduce visual/ information overload, enabling the removal or obscuring of signage when not needed.

2.14. Ensure lighting supports effective visual and task performance levels. 


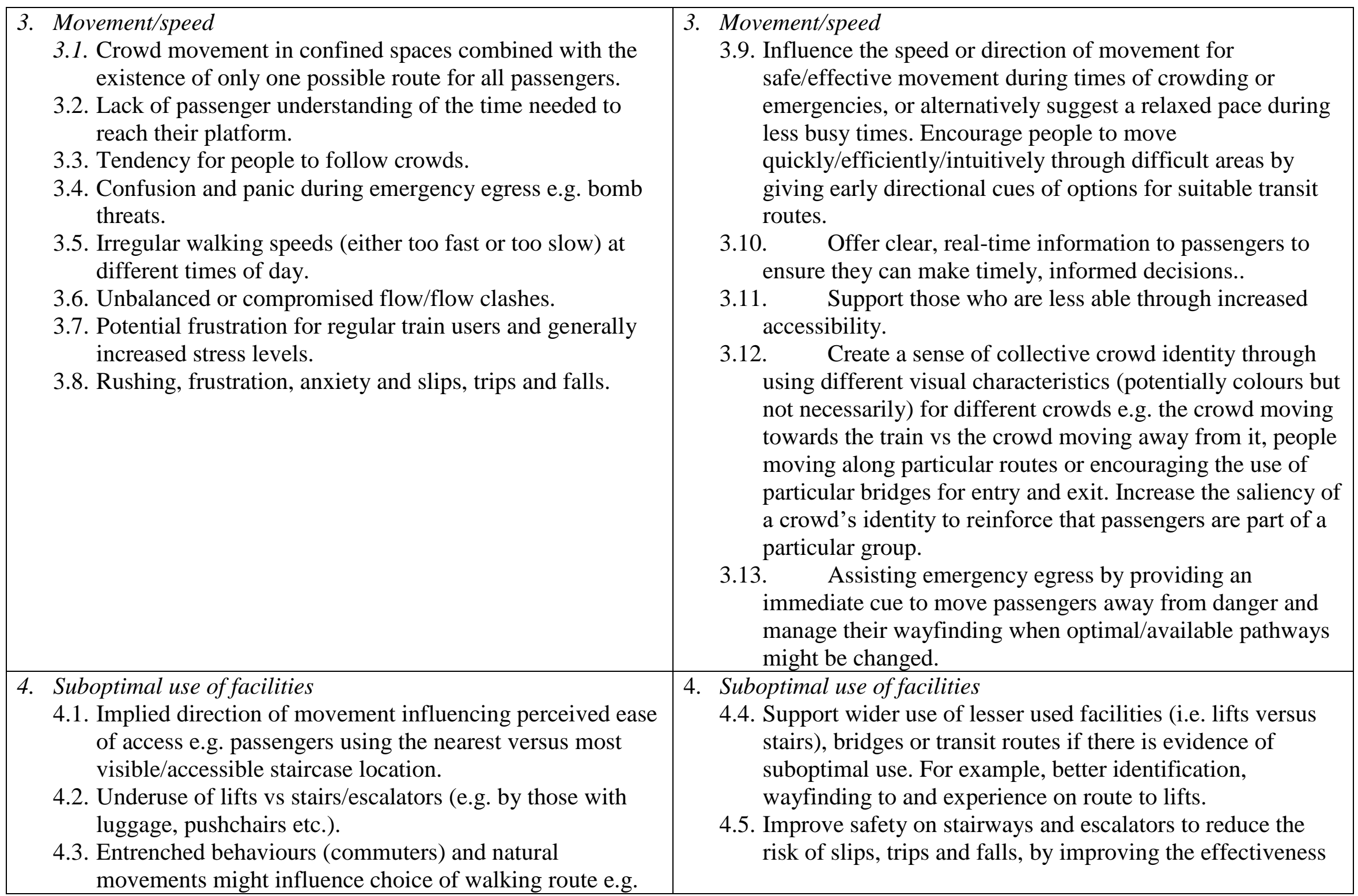




\begin{tabular}{|c|c|}
\hline $\begin{array}{l}\text { side of the staircase or walkway, which might not be the } \\
\text { most efficient/safest. }\end{array}$ & $\begin{array}{l}\text { and efficiency of movement e.g. introducing contra flows, } \\
\text { regulating pace etc. }\end{array}$ \\
\hline $\begin{array}{l}\text { 5. Interaction with the train } \\
\text { 5.1. Risk of falling in between train and platform when } \\
\text { boarding/alighting. } \\
\text { 5.2. Last minute boarding leading to delays in train dispatch. } \\
\text { 5.3. Passengers on the platform blocking those trying to alight. } \\
\text { 5.4. Hesitating before boarding. } \\
\text { 5.5. Passengers/luggage/other items becoming stuck in train } \\
\text { doors. } \\
\text { 5.6. Poor visibility for the driver of the full length of the train. } \\
\text { 5.7. Standing too close to the platform edge, walking over the } \\
\text { safety line on the platform. }\end{array}$ & $\begin{array}{l}\text { 5. Interaction with the train } \\
\text { 5.8. Speed up boarding by encouraging people to let others } \\
\text { alight before they board. } \\
\text { 5.9. Providing reassurance (through real-time information) to } \\
\text { help people who are hesitant, to make confident decisions } \\
\text { e.g. boarding. } \\
\text { 5.10. Helping people to move quickly and safely along the } \\
\text { platform when a train is due to depart. } \\
\text { 5.11. Direct people to the safest place on the } \\
\text { platform/away from the most dangerous areas, by for } \\
\text { example highlighting the yellow safety line, which can be at } \\
\text { different distances from the platform edge for different train } \\
\text { types/speeds. }\end{array}$ \\
\hline $\begin{array}{l}\text { 6. Passenger responses to the environment } \\
\text { 6.1. Passengers or groups of passengers may have additional } \\
\text { needs, which require a response from station staff or the } \\
\text { use of particular facilities. } \\
\text { 6.2. Some passengers may have visual difficulties when } \\
\text { transitioning from a well-lit train to dark platform. } \\
\text { 6.3. Passengers spend more time on less appealing platforms, } \\
\text { than on the concourse (retail area with a more } \\
\text { welcoming/calming environment). } \\
\text { 6.4. Everyday travel can cause a heightened sense of anxiety, } \\
\text { which might be exacerbated for infrequent passengers or } \\
\text { those with mental health issues e.g. sensory overload, } \\
\text { anxiety, aggression/micro-aggression during commuting. }\end{array}$ & $\begin{array}{l}\text { 6. Passenger responses to the environment } \\
\text { 6.5. Identify disabilities/accessibility needs and direct particular } \\
\text { people to assistance. } \\
\text { 6.6. Provide a good experience for all passengers, plus support a } \\
\text { need for economic sustainability of stations. Stations could } \\
\text { be re-imagined as a destination in-and-of-itself. } \\
\text { 6.7. Create a more positive (engaging, enjoyable, welcoming, } \\
\text { personalised and sensory) experience, and influence } \\
\text { affective state in order to create a particular atmosphere } \\
\text { when there are certain events nearby e.g. football matches, } \\
\text { concerts etc. } \\
\text { 6.8. Increase the number of passengers making use of retail, } \\
\text { dining and entertainment options including outside of rush } \\
\text { hours, so facilities/ assets are maximised. } \\
\text { 6.9. Help people to feel more relaxed in the station. }\end{array}$ \\
\hline 7. Crime/ anti-social behaviour & 7. Crime/ anti-social behaviour \\
\hline
\end{tabular}




\begin{tabular}{|c|c|}
\hline $\begin{array}{l}\text { 7.1. Groups of people mis-using the station e.g. trespass, } \\
\text { loitering at night time. } \\
\text { 7.2. Presence of people who are drunk or rushing. } \\
\text { 7.3. Unsteady walking e.g. passengers under the influence of } \\
\text { drugs/alcohol. } \\
\text { 7.4. Threat of terrorism. } \\
\text { 7.5. Fatalities i.e. trespass, suicide and accidents. } \\
\text { 7.6. Passengers feeling unsafe. } \\
\text { 7.7. Criminal or adverse behaviour such as jumping barriers; } \\
\text { creating a risk of injury to oneself/others; damage to } \\
\text { station property; creating a threatening/stressful } \\
\text { environment for others. }\end{array}$ & $\begin{array}{l}\text { 7.8. Reduce affordances/opportunities for crime or reduce the } \\
\text { attractiveness of the area for those who mean to commit } \\
\text { crimes (e.g. discourage loitering). } \\
\text { 7.9. Improve the sense of security for passengers and improve/ } \\
\text { maintain staff safety. } \\
\text { 7.10. Facilitate passengers who are under the influence to } \\
\text { avoid accidents. } \\
\text { 7.11. Address adverse behaviour such as entering an } \\
\text { unauthorised area. } \\
\text { 7.12. Facilitate the identification of those with suicidal } \\
\text { intent in order for timely intervention. }\end{array}$ \\
\hline
\end{tabular}


Table 2. Key scenarios and proposals for innovative lighting interventions

\begin{tabular}{|c|c|c|}
\hline Behaviour/issue & Location(s) & Proposals for lighting interventions \\
\hline $\begin{array}{l}\text { Scenario } 1 \\
\text { Passengers are unsure of the } \\
\text { optimum position to wait on } \\
\text { a platform for a particular } \\
\text { train/carriage, potentially } \\
\text { restricting alighting (due to } \\
\text { blocking) and affecting } \\
\text { orderly and timely boarding }\end{array}$ & Platform & $\begin{array}{l}\text { 1. Projected zones of light to indicate preferable/designated areas for passengers to wait or } \\
\text { congregate for optimum boarding and alighting } \\
\text { 1.1. Potential to use red, amber, green colours (if compliant with regulations - and only } \\
\text { visible in one direction) to highlight where best to stand. } \\
\text { 1.2. Directional/projected visual representation of the incoming train e.g. carriage/door } \\
\text { locations, disability facilities, cycle areas etc. } \\
\text { 1.3. Bathing the platform/carriage in light to indicate capacity and give an idea of the load } \\
\text { of each carriage. } \\
\text { 1.4. Inconsistencies of light to encouragelenable dispersion to designated/preferable areas } \\
\text { e.g. away from the bottom of a stairway (exiting) or further along a platform. } \\
\text { 1.5. Increased/focused lighting creates interest and engagement }{ }^{53} \text {. Create pools of light } \\
\text { (warm-white CCT/orange) to encourage people to stand in particular areas e.g. cooler } \\
\text { areas for cross passages, warmer for waiting areas. } \\
\text { 1.6. Warm coloured (CCT), accent lighting used in highlighting products / features has a } \\
\text { positive effect, increasing engagement }{ }^{10} \text {. Create strips of light (warm-white } \\
\text { CCT/orange) to encourage people to stand in lines, possibly pulsating to attract } \\
\text { attention/have a calming effect. }\end{array}$ \\
\hline $\begin{array}{l}\text { Scenario } 2 \\
\text { Passengers are reluctant to } \\
\text { move down the length of the } \\
\text { platform whilst waiting for a } \\
\text { particular train, creating } \\
\text { bunching and blockages }\end{array}$ & Platform & $\begin{array}{l}\text { 2. Projected zones of light to indicate preferable/designated areas for passengers to wait i.e. } \\
\text { distribute along a platform } \\
\text { 2.1. Pulsing light to entice passengers further down the platform. } \\
\text { 2.2. Illuminate the full length of the train/the ends of the platform (that are not always in } \\
\text { use) when long trains are due. } \\
\text { 2.3. Pools of light to highlight the expected location of the train on the platform or to } \\
\text { indicate how many free seats will be further down the platform. } \\
\text { 2.4. Warmer white light (2700k) is recognised as more relaxing, enjoyable and, within a } \\
\text { retail context, more 'welcoming' }{ }^{36} \text {. Use differences in CCT to encourage/discourage } \\
\text { waiting in different areas }\end{array}$ \\
\hline
\end{tabular}




\begin{tabular}{|c|c|c|}
\hline $\begin{array}{l}\text { Scenario } 3 \\
\text { Passengers are unclear of the } \\
\text { optimum routes and exits on } \\
\text { alighting a train, causing } \\
\text { uncertainty and blockages } \\
\text { (and potentially slips, trips } \\
\text { and falls, particularly on } \\
\text { stairways) }\end{array}$ & $\begin{array}{l}\text { Platform/ent } \\
\text { rances } \\
\text { (including } \\
\text { stairways) } \\
\text { and exits }\end{array}$ & $\begin{array}{l}\text { 3. Projected directional lights to indicate optimum routes for passengers to disperse, } \\
\text { through/out of the station. } \\
\text { 3.1. Introduce zoning by highlighting "portals" to exits or to different parts of the station } \\
\text { to encourage route choice, working in conjunction with physical space/features. } \\
\text { 3.2. Laser lighting lines to define the horizontal plane/paths } 52 \\
\text { 3.3. Bathing lights to emphasize and encourage the use of particular entrances (including } \\
\text { stairways)/exists } \\
\text { 3.4. Light is a significant wayfinding factor and although signage is still the default choice, } \\
\text { people will choose brightness over width in corridor or route selection } 21 \text {, } 22 \text {. Use } \\
\text { differences in brightness for wayfinding to different areas of the station when a number } \\
\text { of route options are available. } \\
\text { 3.5. Neutral CCT supports wayfinding and orientation tasks }{ }^{37} \text {. Use of different CCT for } \\
\text { wayfinding for different purposes/time of day. } \\
\text { 3.6. Illuminate features e.g. escalators and gate lines, and down-lighting walls/information. } \\
\text { 3.7. Visual cues for alternative/preferable options (including lifts versus stairs), similar to } \\
\text { emergency exit lights on aircraft. } \\
\text { 3.8. Red and green lighting to indicate closed/open ticket gates, which could be linked, } \\
\text { through sensors or other technologies, to train/station capacity data. }\end{array}$ \\
\hline $\begin{array}{l}\text { Scenario } 4 \\
\text { Passengers are unsure of } \\
\text { which side to walk in bi- } \\
\text { directional flows, causing } \\
\text { bunching and bottlenecks } \\
\text { (and potentially slips, trips } \\
\text { and falls, particularly on } \\
\text { stairways) }\end{array}$ & $\begin{array}{l}\text { Stairways, } \\
\text { bridges, } \\
\text { walkways }\end{array}$ & $\begin{array}{l}\text { 4. Pulsating and/or chasing track lighting on walls and handrails to indicate the 'direction' and } \\
\text { pace of passenger (bi-directional) flows. } \\
\text { 4.1. Colour coded lights (red/stop: green/go) to indicate the direction of (bi-directional) } \\
\text { flows, although these must not compromise safety critical station operations. For } \\
\text { example, use green arrows and red crosses on the lip of stairs/escalators to indicate } \\
\text { 'up' and 'down' zones', or strip lighting on the lip of stairs/escalators to draw attention } \\
\text { to the area. } \\
\text { 4.2. Use of flowing LED track lighting (wall/handrail mounted) to support movement } \\
\text { paths/pace. } \\
\text { 4.3. Coloured lighting to assist wayfinding, e.g. different coloured routes. If it is to be used } \\
\text { to create a crowd identity, it could work with other kinds of signage, e.g. all exiting } \\
\text { passengers follow red signs, all for platform } 2 \text { follow purple signs etc. This colour } \\
\text { (etc.) could move with the crowd and adapt to changes in the crowd, for example, } \\
\text { people might join different groups as they move through the station. }\end{array}$ \\
\hline
\end{tabular}




\begin{tabular}{|c|c|c|}
\hline & & $\begin{array}{l}\text { 4.4. Control the 'up' and 'down' flow in stairways/escalators by varying the width of a } \\
\text { projected light across the stairway/escalator according to capacity/demand. } \\
\text { Overhead lighting to maintain task related performance. } \\
\text { 4.5. Higher flicker rates (32,000Hz) were found to have a positive effect upon attention } 48 \text {; } \\
\text { and as such a higher, imperceptible flicker rate could heighten general 'activation' } \\
\text { levels and thus stimulating quicker decision-making. Use higher flicker rates to assist } \\
\text { general wayfinding. }\end{array}$ \\
\hline $\begin{array}{l}\text { Scenario } 5 \\
\text { Passengers walk at an } \\
\text { inappropriate speed, either } \\
\text { walking too slowly or too } \\
\text { quickly during different } \\
\text { crowding conditions, causing } \\
\text { delays and risks of slips, trips } \\
\text { and falls or platform-train } \\
\text { interface incidents }\end{array}$ & $\begin{array}{l}\text { Stairways, } \\
\text { bridges, } \\
\text { walkways }\end{array}$ & $\begin{array}{l}\text { 5. Chasing and pulsating lights to indicate appropriate pace of walking. } \\
\text { 5.1. Use of dimmed lighting (responsively increasing to 100\%) along a path to induce } \\
\text { slower walking speeds, or the use of pulsating lighting (slower tempo) to regulate } \\
\text { walking speeds. } \\
\text { 5.2. Flashing or flowing lights or projecting arrows along bridges and walkways. } \\
\text { 5.3. Colour, intensity or position of the lighting could change the visual appearance, e.g. a } \\
\text { sense of widening or narrowing of walkways encourage movement or encourage use of } \\
\text { different parts of the walkway such as staying near to handrails. } \\
\text { 5.4. Count down timer to suggest an acceptable speed of walking. } \\
\text { 5.5. Use of high frequency/non visual flicker, which has a positive effect upon cognitive } \\
\text { processing and problem solving } 48 \\
\text { 5.6. Slower tempo music can reduce walking speeds }{ }^{63} \text { (similar affordance effects are } \\
\text { proposed with lighting) } \\
\text { 5.7. Use of cool-white light (5000k) or 'blue-shifted' light for increases in levels of } \\
\text { 'activation', subjective alertness, and well-being } 46 \text {, and warmer white light (2700k) for } \\
\text { more relaxing, enjoyable and, within a retail context, more 'welcoming' } 36 \text { experiences. }\end{array}$ \\
\hline $\begin{array}{l}\text { Scenario } 6 \\
\text { Passenger movements need } \\
\text { to be managed during } \\
\text { emergencies and in unsafe } \\
\text { locations/events. }\end{array}$ & $\begin{array}{l}\text { Platform } \\
\text { ends, across } \\
\text { the station }\end{array}$ & $\begin{array}{l}\text { 6. Changes to brightness and/or colour to attract/discourage attention } \\
\text { 6.1. A distinctive change in light conditions to highlight a sudden change to the } \\
\text { environment when it reaches a certain capacity or when there is an emergency } \\
\text { situation, similar to when lights go on in a theatre at the end of a play to indicate a } \\
\text { change in status. This could involve a natural, warm lighting for everyday situations, } \\
\text { and a harsh, cold light for emergencies. } \\
\text { 6.2. Use of PIR activated flashing or coloured lighting (e.g. cool-white or blue-shifted light } \\
{ }^{46} \text { ) to highlight/draw staff attention to negative behaviours such as entering an }\end{array}$ \\
\hline
\end{tabular}




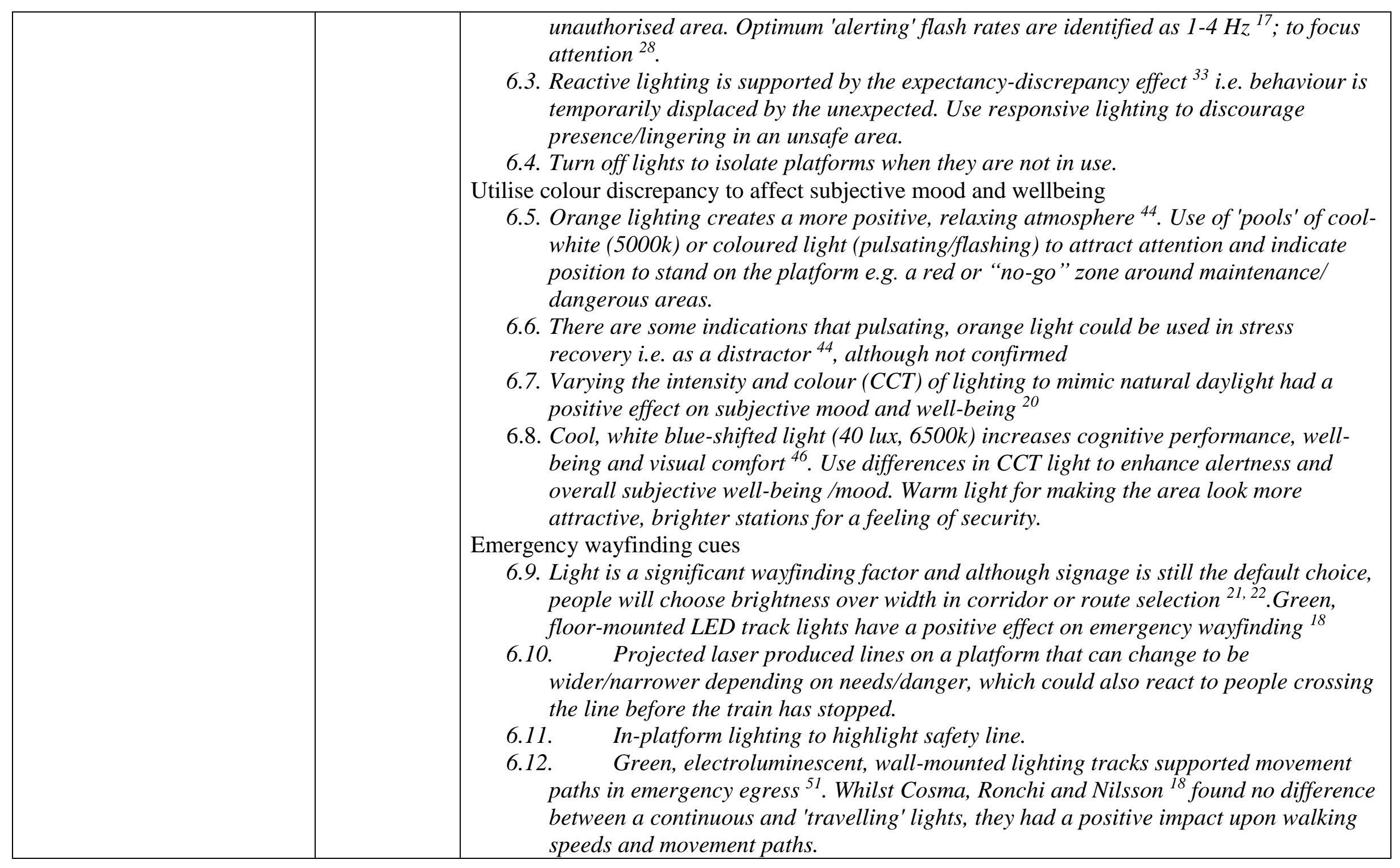


